\title{
Chalcogenide suspended-core fibers for supercontinuum generation in the mid-infrared
}

\author{
Enrico Coscelli ${ }^{a}$, Federica Poli ${ }^{a}$, Jianfeng Li $^{b, c}$, Annamaria Cucinotta ${ }^{a}$ and Stefano Selleri ${ }^{a}$ \\ ${ }^{a}$ Information Engineering Department, University of Parma, I-43124 Parma, Italy; \\ ${ }^{b}$ State Key Laboratory of Electronic Thin Films and Integrated Devices, School of \\ Optoelectronic Information, University of Electronic Science and Technology of China \\ (UESTC), Chengdu 610054, China; \\ ${ }^{c}$ Institute of Photonic and Technology (AIPT), Aston University, Birmingham, United \\ Kingdom
}

\begin{abstract}
Chalcogenide suspended core fibers are a valuable solution to obtain supercontinuum generation of light in the mid-infrared, thanks to glass high transparency, high index contrast, small core diameter and widely-tunable dispersion. In this work the dispersion and nonlinear properties of several chalcogenide suspended core microstructured fibers are numerically evaluated, and the effects of all the structural parameters are investigated. Optimization of the design is carried out to provide a fiber suitable for wide-band supercontinuum generation in the mid-infrared.
\end{abstract}

Keywords: Microstructured fibers, Dispersion engineering, Supercontinuum generation, Nonlinear fibers, Chalcogenide optical fibers, Mid-infrared sources

\section{INTRODUCTION}

Recently, chalcogenide glass based optical devices have attracted great attention because of their potential applications in telecom such as signal regeneration, ${ }^{1}$ wavelength conversion in the infrared using Raman shifting ${ }^{2,3}$ and mid-IR supercontinuum generation. ${ }^{4-6}$ Chalcogenide glasses are based on a mixture of chalcogen elements: sulphur, selenium, or tellurium and other elements such as arsenic, germanium, antimony, or gallium. Compared to silica glasses, they offer extraordinary nonlinear characteristics, i.e. their nonlinear refractive index can be 800 times higher than that of silica fiber, ${ }^{1}$ low two-photon absorption, ${ }^{7}$ and excellent transmission window that extends far into the infrared (IR) spectral region, up to $10 \mu \mathrm{m}, 12 \mu \mathrm{m}$, and $20 \mu \mathrm{m}$ for $\mathrm{S}$, Se, and Te based glasses, respectively. However, higher refractive index of chalcogenide glasses compared to silica leads to longer material Zero Dispersion Wavelength (ZDW) of about $4.5 \mu \mathrm{m} .^{6}$ This feature is harmful for the applications in mid-infrared non-linear optics, e.g., the large normal GVD at telecom wavelengths distorts ultra-short optical pulses ${ }^{8}$ and the long ZDW does not allow an anomalous dispersion pumping for broad band SuperContinuum (SC) generation. To harness the useful features of chalcogenide glasses, control of chromatic dispersion while keeping high nonlinear coefficient must be addressed.

Suspended-Core Fiber (SCF) is an excellent candidate for further enhancing of nonlinear properties and tuning of dispersion..$^{9,10}$ The small core and high NA of SCF ensure tight confinement of light and high nonlinearity. Besides, low loss, high air-filling fraction, and ultra low mode field diameter have attracted designers to exploit the SCFs for different nonlinear applications. The most important applications of chalcogenide SCFs at present are wavelength conversion ${ }^{11-13}$ and SC generation. ${ }^{14,15}$ Wavelength conversion from $2 \mu \mathrm{m}$ to $4.5 \mu \mathrm{m}$ has been observed in $\mathrm{As}_{2} \mathrm{~S}_{5} \mathrm{SCF}$ with ZDW at $2 \mu \mathrm{m}$ by degenerate four-wave mixing. ${ }^{11}$ Soliton self-frequency shift and third-harmonic generation has been observed in a four-hole tapered $\mathrm{As}_{2} \mathrm{~S}_{5} \mathrm{SCF}$ with ZDW at $1.61 \mu \mathrm{m}$ pumped by $1.55 \mu \mathrm{m}$ pulsed laser. ${ }^{12}$ Fourth order cascaded Raman wavelength shifting from $2092 \mathrm{~nm}$ to $2450 \mathrm{~nm}$ was demonstrated in a low loss $\mathrm{As}_{38} \mathrm{Se}_{62} \mathrm{SCF}$ with ZDW of $3.15 \mu \mathrm{m}$ pumped by $1995 \mathrm{~nm}$ Tm-doped gain switched

Further author information: (Send correspondence to Enrico Coscelli)

Enrico Coscelli: E-mail: enrico.coscelli@unipr.it

Nonlinear Frequency Generation and Conversion: Materials, Devices, and Applications XIV, edited by Konstantin L. Vodopyanov, Proc. of SPIE Vol. 9347, 93471P · (C) 2015 SPIE CCC code: $0277-786 \mathrm{X} / 15 / \$ 18 \cdot$ doi: $10.1117 / 12.2077431$

Proc. of SPIE Vol. 9347 93471P-1 

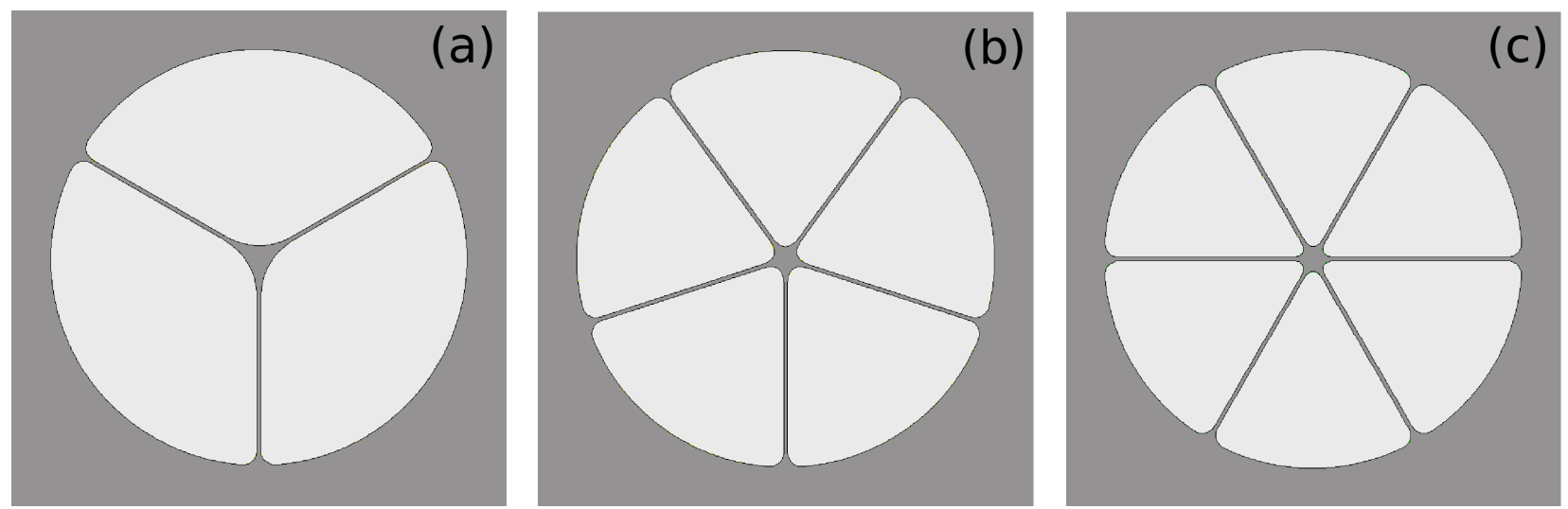

Figure 1. Cross-section of the considered chalcogenide SCF with (a) 3 bridges, (b) 5 bridges and (c) 6 bridges.
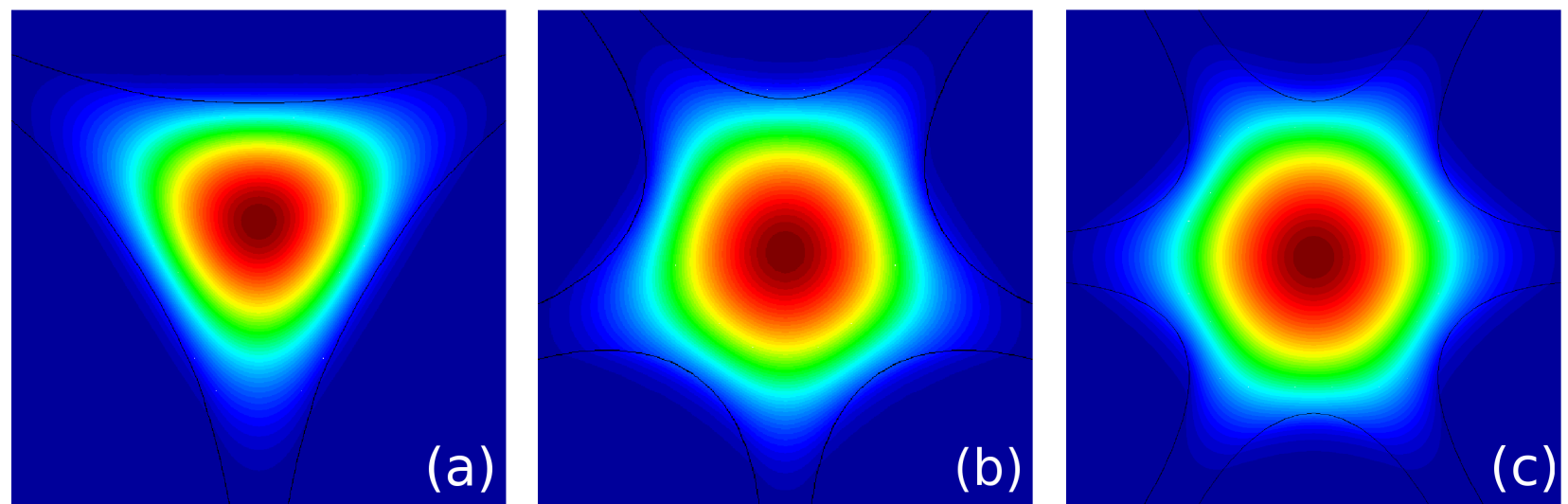

Figure 2. Magnetic field modulus distribution of the fundamental mode, calculated at $\lambda=2000 \mathrm{~nm}$, for the SCF with (a) 3 bridges, (b) 5 bridges and (c) 6 bridges.

laser. ${ }^{13} \mathrm{~A}$ mid-IR SC spanning from 1 to $4 \mu \mathrm{m}$ has been experimentally demonstrated in $\mathrm{As}_{2} \mathrm{~S}_{3} \mathrm{SCF}$ with ZDW of $1660 \mathrm{~nm}$ pumped by an OPO laser with tunable wavelength from $1.7 \mu \mathrm{m}$ to $2.6 \mu \mathrm{m} .{ }^{14}$ Then, a mid-IR SC spanning from $1.5 \mu \mathrm{m}$ to $4.5 \mu \mathrm{m}$ was also achieved in $\mathrm{As}_{2} \mathrm{~S}_{3}$ SCF with ZDW of $2.52 \mu \mathrm{m}$ pumped by an OPO laser with tunable wavelength from $2.2 \mu \mathrm{m}$ to $2.6 \mu \mathrm{m} .^{15}$

It is observed from the above literature that different chromatic dispersion and nonlinear characteristics are required for different pump wavelengths and applications. Several publications have already addressed the engineering of SCFs, ${ }^{10,16-18}$ but a comprehensive study devoted to a thorough analysis of the effects of all the cross-section parameters on the fiber properties has not been presented yet. The aim of this paper is to provide useful guidelines for designing SCFs for mid-IR applications. The dispersion and nonlinear properties of chalcogenide SCFs have been numerically studied by taking into account all the main design parameters, that is, besides the core radius, the thickness and number of the glass bridges that intersect to create the core. The results have shown that all these parameters can be combined to shape the SCF dispersion properties to match the specific requirements of any application.

\section{MODELING OF CHALCOGENIDE SCF}

The cross-section of the chalcogenide SCFs that have been considered, that is with 3,5 and 6 air-holes in the cladding, separated by the same number of thin glass bridges, are shown in Fig. 1(a)-(c). The fiber core is created by the intersection of the glass bridges, which are linked by parabolic-shaped connectors. The crosssection has a $\mathrm{C}_{n}$ symmetry, being $n$ the number of bridges. The guiding properties of these fibers are determined by four main parameters, that are the core radius $r_{c}$, which is the radius of the largest circumference inscribed into the core, the strut number and thickness $t$, and the glass composition, which influences material dispersion and nonlinearity. Values of $r_{c}$ in the range of $0.5 \mu \mathrm{m}-1.5 \mu \mathrm{m}$ and $t$ between $0.15 \mu \mathrm{m}$ and $0.45 \mu \mathrm{m}$ have been 

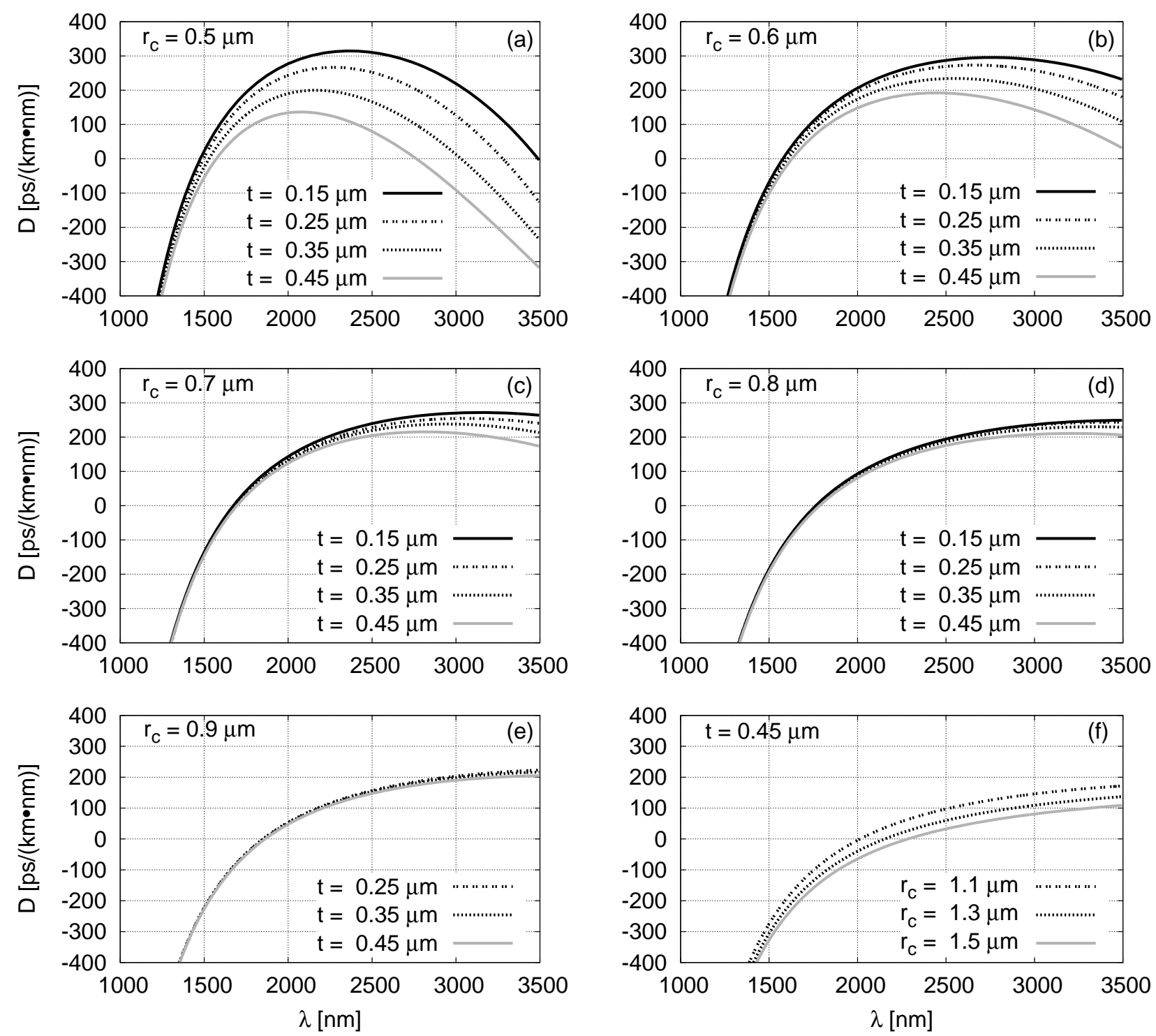

Figure 3. Dispersion parameter versus wavelength of the SCFs with 3 bridges and core radius of (a) $0.5 \mu \mathrm{m}$, (b) $0.6 \mu \mathrm{m}$, (c) $0.7 \mu \mathrm{m}$, (d) $0.8 \mu \mathrm{m}$, (e) $0.9 \mu \mathrm{m}$ and different values of bridge thickness. (f) Dispersion parameter versus wavelength of the SCFs with 3 bridges and core radius from $1.1 \mu \mathrm{m}$ to $1.5 \mu \mathrm{m}$, with $t=0.45 \mathrm{~nm}$.

considered, which are appropriate for technologically-feasible chalcogenide fibers or, at least, can be reached by tapering over lengths of several centimeters. ${ }^{14,18,19}$ The length of the struts is about $20 \mu \mathrm{m}$, in order to prevent leakage of the fundamental mode into the cladding. $\mathrm{As}_{2} \mathrm{~S}_{3}$ chalcogenide glass has been considered for the simulations, because of its high infrared transparency, up to $10 \mu \mathrm{m}$, high nonlinear coefficient and good drawing capability. ${ }^{18}$ The refractive index of $\mathrm{As}_{2} \mathrm{~S}_{3}$ has been calculated according to the Sellmeier equation:

$$
n^{2}(\lambda)=1+\sum_{i} \frac{A_{i} \lambda^{2}}{\lambda^{2}-\lambda_{i}^{2}}
$$

being $A_{1}=1.8983678, A_{2}=1.9222979, A_{3}=0.8765134, A_{4}=0.1188704, A_{5}=0.9569903, \lambda_{1}^{2}=0.0225 \mu \mathrm{m}^{2}$, $\lambda_{2}^{2}=0.0625 \mu \mathrm{m}^{2}, \lambda_{3}^{2}=0.1225 \mu \mathrm{m}^{2}, \lambda_{4}^{2}=0.2025 \mu \mathrm{m}^{2}, \lambda_{5}^{2}=750 \mu \mathrm{m}^{2}{ }^{20}$

The fundamental mode of the SCFs has been obtained by means of a full-vector modal solver based on the finite-element method, ${ }^{21}$ in the wavelength range from $1000 \mathrm{~nm}$ to $3500 \mathrm{~nm}$. The modal solver has been already 

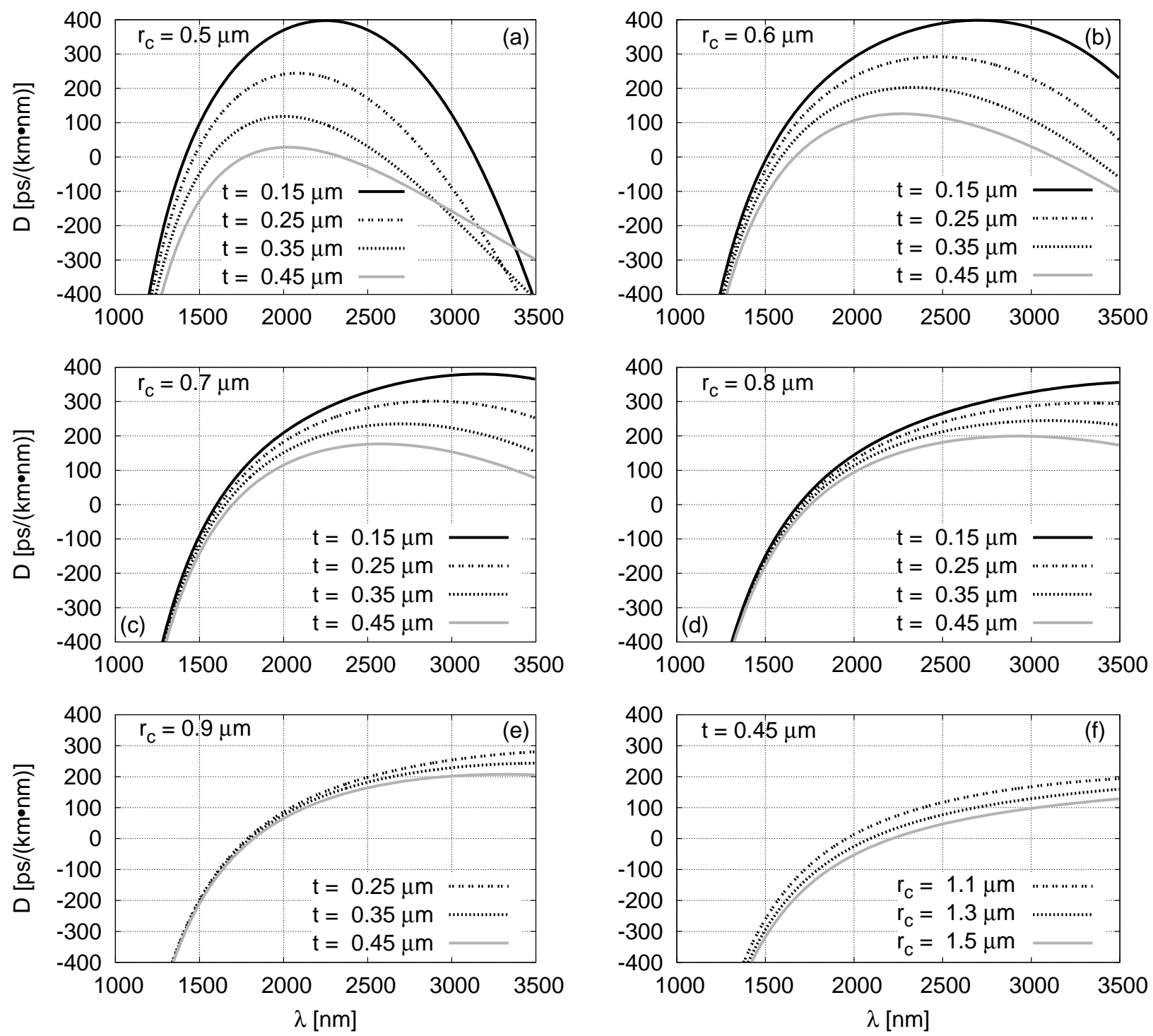

Figure 4. Dispersion parameter versus wavelength of the SCFs with 5 bridges and core radius of (a) $0.5 \mu \mathrm{m}$, (b) $0.6 \mu \mathrm{m}$, (c) $0.7 \mu \mathrm{m}$, (d) $0.8 \mu \mathrm{m}$, (e) $0.9 \mu \mathrm{m}$ and different values of bridge thickness. (f) Dispersion parameter versus wavelength of the SCFs with 5 bridges and core radius from $1.1 \mu \mathrm{m}$ to $1.5 \mu \mathrm{m}$, with $t=0.45 \mathrm{~nm}$.

applied with success to the analysis of the dispersion properties of several PCFs. ${ }^{22-25}$ The magnetic field modulus distribution of the fundamental mode, calculated at $\lambda=2000 \mathrm{~nm}$ for the SCF with 3,5 and 6 bridges, is shown in Fig. 2(a)-(c), respectively.

\section{DISPERSION ENGINEERING}

Fig. 3(a) shows the dispersion parameter $D$ versus the wavelength obtained for the SCFs with 3 bridges, $r_{c}=0.5 \mu \mathrm{m}$ and different strut thickness values. Thanks to the large waveguide dispersion achieved with the small core diameter, all the considered fibers present two different zero dispersion wavelengths below $3.5 \mu \mathrm{m}$, the lowest one being conveniently located at $\lambda_{Z D W, 1} \cong 1500 \mathrm{~nm}$. Notice that bulk $\mathrm{As}_{2} \mathrm{~S}_{3}$ has negative dispersion throughout the considered range and presents a single ZDW at $\lambda=4.9 \mu \mathrm{m} .{ }^{20}$ Remarkably the bridge thickness $t$, which has been usually neglected in previous works, has a strong impact on the dispersion properties. In particular, larger struts cause an overall decrease of $D$, whose maximum value is over $300 \mathrm{ps} /(\mathrm{km} \cdot \mathrm{nm})$ in the 

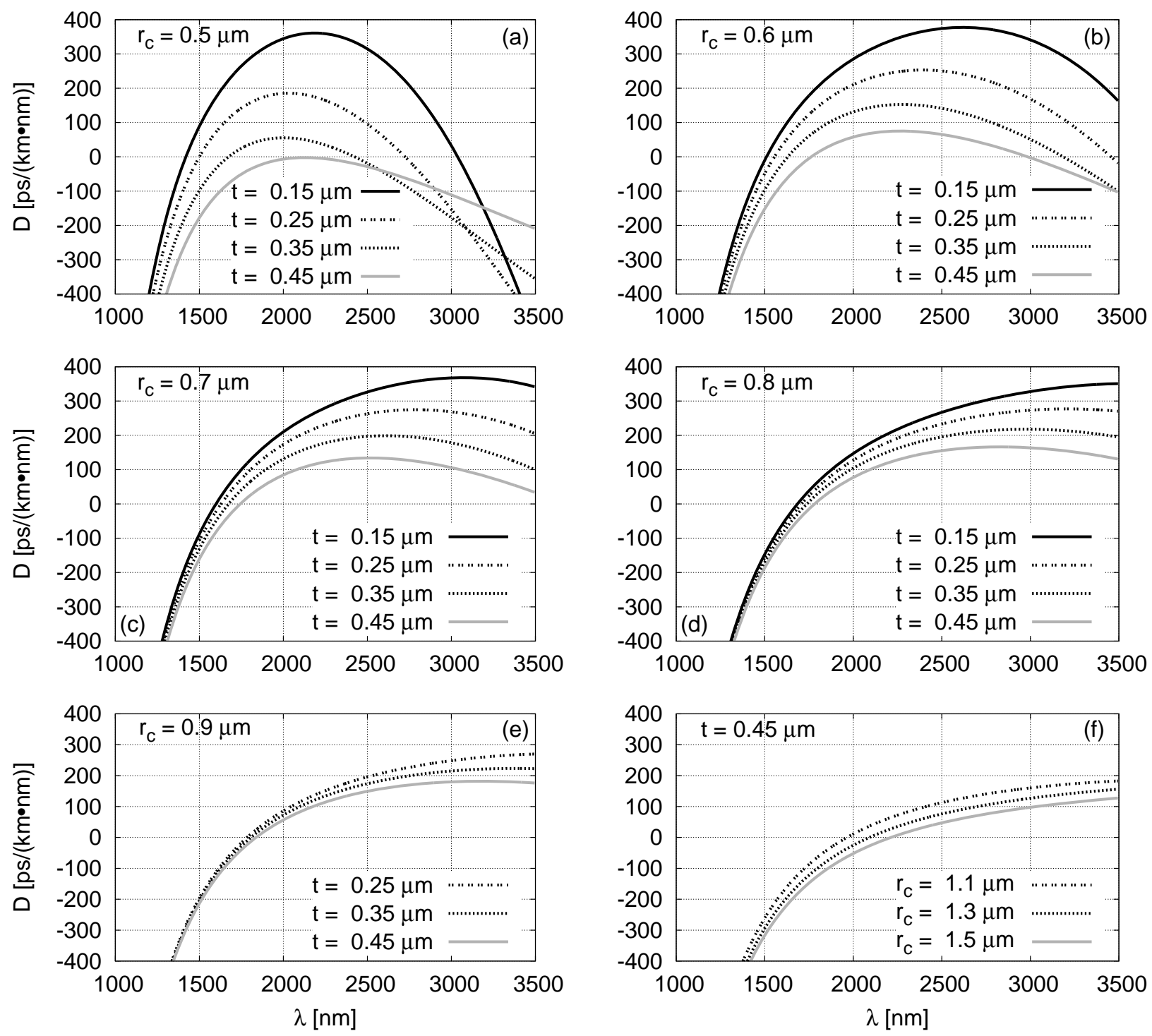

Figure 5. Dispersion parameter versus wavelength of the SCFs with 6 bridges and core radius OF (a) $0.5 \mu \mathrm{m}$, (b) $0.6 \mu \mathrm{m}$, (c) $0.7 \mu \mathrm{m}$, (d) $0.8 \mu \mathrm{m}$, (e) $0.9 \mu \mathrm{m}$ and different values of bridge thickness. (f) Dispersion parameter versus wavelength of the SCFs with 6 bridges and core radius from $1.1 \mu \mathrm{m}$ to $1.5 \mu \mathrm{m}$, with $t=0.45 \mathrm{~nm}$.

SCF with $t=0.15 \mu \mathrm{m}$ and only $130 \mathrm{ps} /(\mathrm{km} \cdot \mathrm{nm})$ in the fiber with $t=0.45 \mu \mathrm{m}$. More interestingly, the increase of the bridge thickness causes the distance between the two ZDWs to narrow, mostly by blue-shifting the second ZDW. As a result, $\lambda_{Z D W, 2}=2763 \mathrm{~nm}$ when $t=0.45 \mu \mathrm{m}$, while it is $3489 \mathrm{~nm}$ for $t=0.15 \mu \mathrm{m}$.

Fig. 3(b)-(e) report the curves of the dispersion of SCFs with larger $r_{c}$, up to $0.9 \mu \mathrm{m}$. Notice that the increase of the core size causes an overall red shift of the curves and a broadening of the regime where the fibers operate in anomalous dispersion. Furthermore, the dispersion is progressively flattened and $\lambda_{Z D W, 2}$ is shifted far outside from the considered wavelength range. The influence of the bridge thickness is greatly reduced in the SCFs with larger core, and no significant effects are observed when $r_{c} \geq 0.9 \mu \mathrm{m}$. Therefore the bridge thickness has been neglected for the SCF with core radius larger than $1 \mu \mathrm{m}$, whose dispersion is shown in Fig. 3(f) for $t=0.45 \mu \mathrm{m}$. Again, lower overall $D$ values are obtained with the increase of the core size, and $\lambda_{Z D W, 1}$ is further shifted towards longer wavelengths, up to $2284 \mathrm{~nm}$ for $r_{c}=1.5 \mu \mathrm{m}$.

Further degrees of freedom for the dispersion engineering of SCFs can be provided by the choice of the number 


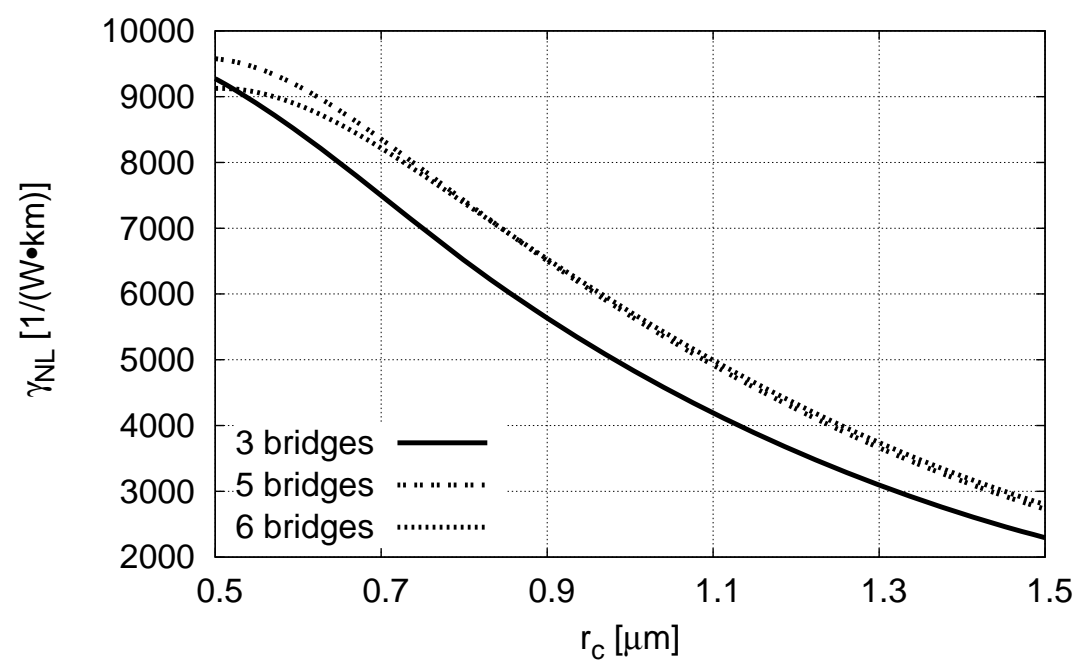

Figure 6. Nonlinear coefficient $\gamma_{N L}$ of the considered SCFs with different core size and $t=0.45 \mu \mathrm{m}$, calculated at $\lambda=2000 \mathrm{~nm}$.

of bridges, which influence the shape of the core and the field distribution. Fig. 4(a)-(e) report the calculated dispersion parameter for the fibers with 5 -fold symmetry, core radius between $0.5 \mu \mathrm{m}$ and $0.9 \mu \mathrm{m}$ and different $t$ values. The most remarkable effect of the increased number of struts is that their thickness has a stronger impact on the dispersion properties, especially if small cores are considered. For example, by comparing Fig. 3(a) and Fig. 4(a) it is clear that a larger anomalous dispersion, up to $400 \mathrm{ps} /(\mathrm{km} \cdot \mathrm{nm})$, can be achieved with small bridges in 5-fold SCFs with respect to 3-fold ones. The situation is reversed for designs with large struts, being for example the maximum $D$ about $130 \mathrm{ps} /(\mathrm{km} \cdot \mathrm{nm})$ in the 3 -fold SCF with $t=0.45 \mu \mathrm{m} r_{c}=0.5 \mu \mathrm{m}$ and less than $50 \mathrm{ps} /(\mathrm{km} \cdot \mathrm{nm})$ in the 5 -fold fiber with the same structural parameters. Furthermore, in the SCFs with 5 bridges the change of $t$ has a stronger effect on $\lambda_{Z D W, 1}$, which is significantly red-shifted by the increase of the strut width, while it was almost constant in the SCFs with 3 bridges. A larger dispersion slope is also generally observed, yielding to a narrowing of the distance between the two ZDWs, down to about $570 \mathrm{~nm}$ for the PCF with $r_{c}=0.5 \mu \mathrm{m}$ and $t=0.45 \mu \mathrm{m}$. The effect of the bridge width gradually fades out with the increase of the core size, as shown by Fig. 4(b)-(e), and becomes negligible for $r_{c}>1 \mu \mathrm{m}$, as already observed in 3-fold SCFs. Notice also that for these values of the core radius the number of bridges in the cladding is almost unimportant, being the dispersion curves of the 5-fold SCFs, shown in Fig. 4(f), very close to those in Fig. 3(f).

The calculated dispersion of the SCFs with 6 bridges are reported in Fig. 5(a)-(f). For small core diameter, that is for fibers whose dispersion properties are still influenced by the strut thickness, the dispersion is slightly lower than in the 5 -fold counterparts for any given value of $t$. Remarkably, if the parameters $r_{c}=0.5 \mu \mathrm{m}$ and $t=0.45 \mu \mathrm{m}$ are chosen, the fiber operates in normal dispersion regime throughout the whole considered wavelength range, as shown in Fig. 5(a). Again, increasing values of the core radius cause the effect of $t$ on the dispersion properties to become less significant, as the curves converge on those already found for PCFs with 3 and 5 bridges.

In conclusion, a general feature of SCFs can be inferred by these results. For small core radii, namely for $r_{c}<1 \mu \mathrm{m}$, the guidance is severely influenced by the struts, whose size and number can be adjusted to tune the dispersion characteristics. On the contrary, the guiding properties of SCFs with larger core are only marginally affected by the size of the struts, and their dispersion curves have a lower slope, being similar to the one of a step-index fiber with the same NA. Moreover, it is worth noting that the design with 3 bridges allows to blue-shift the material ZDW by more than $3500 \mathrm{~nm}$, by acting only on the values of $r_{c}$ and $t$. SCFs with 3 bridges are easier to manufacture with small core diameters, without requiring tapering, and are the most used so far. The designs with 5 and 6 struts enable a stronger control of the dispersion curve, allowing dual-ZDW dispersion profiles with very close $\lambda_{Z D W}$ and lower dispersion in the anomalous regime, or even all-normal dispersion curves. On the other side, manufacturing of 5-fold and 6-fold SCFs with small cores is more difficult. As a consequence, they 
should be considered only in case that a fine dispersion tailoring is required to provide a significant benefit for the desired application.

\section{NONLINEAR PROPERTIES}

Besides the dispersion control, it is important to provide low effective area and high nonlinear coefficient to enhance the nonlinear properties of the material, in order to fully exploit the potential of SCFs for applications such as wavelength conversion or SC generation. Thanks to the high refractive index of the chalcogenide glass and due to the small fiber core, very small effective area $A_{\text {eff }}$ can be achieved, down to less than $1 \mu \mathrm{m}^{2}$ between $1000 \mathrm{~nm}$ and $1500 \mathrm{~nm}$ for the SCFs with $r_{c}=0.5 \mu \mathrm{m}$, regardless of the number of bridges. $A_{\text {eff }}$ values lower than $4 \mu \mathrm{m}^{2}$ can be obtained at $\lambda=3500 \mathrm{~nm}$, which is the longest wavelength considered in this analysis, in fibers with relatively large core radii, up to $1.1 \mu \mathrm{m}-1.2 \mu \mathrm{m}$. In general, PCFs with more struts provide a smaller $A_{\text {eff }}$ value for a given $r_{c}, \lambda$ pair. This is due to the fact that the guided mode is less prone to expand outside from the glass, because of the smaller air-filling fraction of the cladding.

The combined effect of the high material nonlinearity and of the small effective area provides the possibility to achieve very large nonlinear coefficient $\gamma_{N L}$, which has been calculated according to this formulation:

$$
\gamma_{N L}=\frac{2 \pi}{\lambda} \frac{n_{2, N L}}{A_{e f f, N L}}
$$

being

$$
A_{e f f, N L}=\frac{\left|\int_{S} \bar{E} \times \bar{H}^{*} \cdot \hat{z} d A\right|^{2}}{\int_{S}\left|\bar{E} \times \bar{H}^{*}\right|^{2} \cdot \hat{z} d A}
$$

with $n_{2, N L}=4.2 \cdot 10^{-18} \mathrm{~m}^{2} / \mathrm{W}$ the nonlinear refractive index of $\mathrm{As}_{2} \mathrm{~S}_{3}$ glass ${ }^{26}$ and $S$ the glass domains in the cross-section. ${ }^{27}$ The equation neglects the contribution to overall nonlinearity of air, which is 5 orders of magnitudes lower than $\mathrm{As}_{2} \mathrm{~S}_{3}$ glass.

Fig. 6 shows the curves of the nonlinear coefficient obtained at $\lambda=2000 \mathrm{~nm}$ as a function of the core radius, for the SCFs with 3, 5 and 6 bridges and the largest bridge width $t=0.45 \mu \mathrm{m}$. Very high values of $\gamma_{N L}$ are achieved with small cores, up to more than $9000 \mathrm{~W}^{-1} \cdot \mathrm{km}^{-1}$ with $r_{c}=0.5 \mu \mathrm{m}$. Larger core radii cause the effective area to increase and, as a consequence, a smaller $\gamma_{N L}$ is obtained. Notice that the fibers with 5 and 6 bridges are more nonlinear with respect to the 3-struts ones, having values of $\gamma_{N L} 15 \%-20 \%$ higher for a given core size.

\section{CONCLUSION}

The dispersion and nonlinear properties of $\mathrm{As}_{2} \mathrm{~S}_{3}$ suspended-core fibers have been thoroughly analyzed by means of a full-vector modal solver based on the finite-element method. The possibility to widely tune the position of the ZDWs by acting on the number and size of the glass bridges has been investigated for the first time, showing that they have an impact on the dispersion characteristics which is comparable to the one of the core size. A wide range of possible designs have been considered, providing guidelines for the design of highly nonlinear SCFs to operate in several applications relying on different sources. Moreover, nonlinear properties have been investigated, showing that values of nonlinear coefficient higher than $9000 \mathrm{~W}^{-1} \cdot \mathrm{km}^{-1}$ can be achieved.

\section{ACKNOWLEDGMENTS}

The authors wish to thank Romain Dauliat, Laurent Brilland and Johann Troles for providing useful information about chalcogenide glasses and chalcogenide fiber fabrication.

\section{REFERENCES}

[1] Harbold, J. M., Ilday, F. Ö., Wise, F. W., Sanghera, J. S., Nguyen, V. Q., Shaw, L. B., and Aggarwal, I. D., "Highly nonlinear As-S-Se glasses for all-optical switching," Opt. Lett. 27, 119-121 (Jan 2002).

[2] Désévédavy, F., Renversez, G., Brilland, L., Houizot, P., Troles, J., Coulombier, Q., Smektala, F., Traynor, N., and Adam, J.-L., "Small-core chalcogenide microstructured fibers for the infrared," Appl. Opt. 47, 6014-6021 (Nov 2008). 
[3] Ta'eed, V., Baker, N. J., Fu, L., Finsterbusch, K., Lamont, M. R. E., Moss, D. J., Nguyen, H. C., Eggleton, B. J., Choi, D.-Y., Madden, S., and Luther-Davies, B., "Ultrafast all-optical chalcogenide glass photonic circuits," Opt. Express 15, 9205-9221 (Jul 2007).

[4] Rudy, C. W., Marandi, A., Vodopyanov, K. L., and Byer, R. L., "Octave-spanning supercontinuum generation in in situ tapered $\mathrm{As}_{2} \mathrm{~S}_{3}$ fiber pumped by a thulium-doped fiber laser," Opt. Lett. 38, 2865-2868 (Aug 2013).

[5] Yue, Y., Zhang, L., Yan, Y., Ahmed, N., Yang, J.-Y., Huang, H., Ren, Y., Dolinar, S., Tur, M., and Willner, A. E., "Octave-spanning supercontinuum generation of vortices in an $\mathrm{As}_{2} \mathrm{~S}_{3}$ ring photonic crystal fiber," Opt. Lett. 37, 1889-1891 (Jun 2012).

[6] Wei, C., Zhu, X., Norwood, R. A., Song, F., and Peyghambarian, N., "Numerical investigation on high power mid-infrared supercontinuum fiber lasers pumped at $3 \mu \mathrm{m}, "$ Opt. Express 21, 29488-29504 (Dec 2013).

[7] Zakery, A. and Elliott, S. R., [Optical Nonlinearities in Chalcogenide Glasses and their Applications], Springer Series in Material Science, Dordrecht (2007).

[8] Slusher, R. E., Lenz, G., Hodelin, J., Sanghera, J., Shaw, L. B., and Aggarwal, I. D., "Large Raman gain and nonlinear phase shifts in high-purity $\mathrm{As}_{2} \mathrm{Se}_{3}$ chalcogenide fibers," J. Opt. Soc. Am. B 21, 1146-1155 (Jun 2004).

[9] Afshar V., S., Zhang, W. Q., Ebendorff-Heidepriem, H., and Monro, T. M., "Small core optical waveguides are more nonlinear than expected: experimental confirmation," Opt. Lett. 34, 3577-3579 (Nov 2009).

[10] Ebendorff-Heidepriem, H., Warren-Smith, S. C., and Monro, T. M., "Suspended nanowires: fabrication, design and characterization of fibers with nanoscale cores," Opt. Express 17, 2646-2657 (Feb 2009).

[11] Kuan, P.-W., Li, K., Zhang, G., Wang, X., Zhang, L., Bai, G., Tsang, Y., and Hu, L., "Compact broadband amplified spontaneous emission in $\mathrm{Tm}^{3+}$-doped tungsten tellurite glass double-cladding single-mode fiber," Opt. Mater. Express 3, 723-728 (Jun 2013).

[12] Cheng, T., Usaki, R., Duan, Z., Gao, W., Deng, D., Liao, M., Kanou, Y., Matsumoto, M., Misumi, T., Suzuki, T., and Ohishi, Y., "Soliton self-frequency shift and third-harmonic generation in a four-hole $\mathrm{As}_{2} \mathrm{~S}_{5}$ microstructured optical fiber," Opt. Express 22, 3740-3746 (Feb 2014).

[13] Duhant, M., Renard, W., Canat, G., Nguyen, T. N., Smektala, F., Troles, J., Coulombier, Q., Toupin, P., Brilland, L., Bourdon, P., and Renversez, G., "Fourth-order cascaded Raman shift in AsSe chalcogenide suspended-core fiber pumped at $2 \mu \mathrm{m}, "$ Opt. Lett. 36, 2859-2861 (Aug 2011).

[14] Savelii, I., Mouawad, O., Fatome, J., Kibler, B., Désévédavy, F., Gadret, G., Jules, J.-C., Bony, P.-Y., Kawashima, H., Gao, W., Kohoutek, T., Suzuki, T., Ohishi, Y., and Smektala, F., "Mid-infrared 2000$\mathrm{nm}$ bandwidth supercontinuum generation in suspended-core microstructured Sulfide and Tellurite optical fibers," Opt. Express 20, 27083-27093 (Nov 2012).

[15] Gao, W., El-Amraoui, M., Liao, M., Kawashima, H., Duan, Z., Deng, D., Cheng, T., Suzuki, T., Messaddeq, Y., and Ohishi, Y., "Mid-infrared supercontinuum generation in a suspended-core $\mathrm{As}_{2} \mathrm{~S}_{3}$ chalcogenide microstructured optical fiber," Opt. Express 21, 9573-9583 (Apr 2013).

[16] Chaudhari, C., Suzuki, T., and Ohishi, Y., "Design of Zero Chromatic Dispersion Chalcogenide As2S3 Glass Nanofibers," J. Lightwave Technol. 27, 2095-2099 (Jun 2009).

[17] Szpulak, M. and Fevrier, S., "Chalcogenide As_2 S_3 Suspended Core Fiber for Mid-IR Wavelength Conversion Based on Degenerate Four-Wave Mixing," Photonics Technology Letters, IEEE 21, 884-886 (Jul 2009).

[18] El-Amraoui, M., Fatome, J., Jules, J. C., Kibler, B., Gadret, G., Fortier, C., Smektala, F., Skripatchev, I., Polacchini, C., Messaddeq, Y., Troles, J., Brilland, L., Szpulak, M., and Renversez, G., "Strong infrared spectral broadening in low-loss As-S chalcogenide suspended core microstructured optical fibers," Opt. Express 18, 4547-4556 (Mar 2010).

[19] Gao, W., Liao, M., Yan, X., Kito, C., Kohoutek, T., Suzuki, T., El-Amraoui, M., Jules, J.-C., Gadret, G., Désévédavy, F., Smektala, F., and Ohishi, Y., "Visible Light Generation and Its Influence on Supercontinuum in Chalcogenide $\mathrm{As}_{2} \mathrm{~S}_{3}$ Microstructured Optical Fiber," Applied Physics Express 4(10), 102601 (2011). 
[20] Rodney, W., Malitson, I., and King, T., "Refractive index of Arsenic Trisulfide," J. Opt. Soc. Am. 48, 633-636 (Sep 1958).

[21] Poli, F., Cucinotta, A., and Selleri, S., [Photonic Crystal Fibers. Properties and Applications], Springer Series in Material Science, Dordrecht (2007).

[22] Poli, F., Cucinotta, A., Selleri, S., and Bouk, A., "Tailoring of flattened dispersion in highly nonlinear photonic crystal fibers," IEEE Photonics Technology Letters 16, 1065-1067 (Apr 2004).

[23] Bouk, A., Cucinotta, A., Poli, F., and Selleri, S., "Dispersion properties of square-lattice photonic crystal fibers," Optics Express 12, 941-946 (Mar 2004).

[24] Poli, F., Cucinotta, A., Fuochi, M., Selleri, S., and Vincetti, L., "Characterization of microstructured optical fibers for wideband dispersion compensation," J. Opt. Soc. Am. A 20, 1958-1962 (Oct 2003).

[25] Poli, F., Cucinotta, A., Fuochi, M., Selleri, S., and Vincetti, L., "Dispersion and Nonlinear Properties of Triangular Photonic Crystal Fibers with Large Air-Holes and Small Pitch," in [European Conference on Optical Communication - ECOC2003], (Sep 2003).

[26] El-Amraoui, M., Gadret, G., Jules, J. C., Fatome, J., Fortier, C., Désévédavy, F., Skripatchev, I., Messaddeq, Y., Troles, J., Brilland, L., Gao, W., Suzuki, T., Ohishi, Y., and Smektala, F., "Microstructured chalcogenide optical fibers from $\mathrm{As}_{2} \mathrm{~S}_{3}$ glass: towards new IR broadband sources," Opt. Express 18, 2665526665 (Dec 2010).

[27] Vincetti, L., Maini, M., Poli, F., Cucinotta, A., and Selleri, S., "Numerical analysis of hollow core photonic band gap fibers with modified honeycomb lattice," Optical and Quantum Electronics 38(9-11), 903-912 (2006). 